\title{
IXSEMINESEGES \\ Síndrome da Mancha Branca: Revisão de literatura
}

[White Spot Syndrome Disease: Review]

"Artigo de Revisão/Review"

\author{
Jéssica de Torres Bandeira ${ }^{1 *}$, Renato Souto Maior Muniz de Morais ${ }^{1}$, \\ Suzianny Maria Bezerra Cabral da Silva ${ }^{2}$, Fernando Leandro dos Santos ${ }^{1}$
}

\begin{abstract}
${ }^{1}$ Departamento de Medicina Veterinária, Universidade Federal Rural de Pernambuco, Recife-PE, Brasil. ${ }^{2}$ Departamento de Pesca e Aquicultura, Universidade Federal Rural de Pernambuco, Recife-PE, Brasil. *Autor para correspondência/Corresponding author: E-mail: bandeira.j.t@gmail.com
\end{abstract}

\begin{abstract}
Resumo
A carcinicultura é uma atividade econômica rentável em expansão cujos principais entraves são os surtos de doenças viróticas. Dentre aquelas, destaca-se a Síndrome da Mancha Branca (WSSD), por sua virulência e taxa de mortalidade. O primeiro relato de surto foi na Ásia, em 1992, e desde então o agente se propagou pelos cultivos de camarões em todo o mundo. O Vírus da Síndrome da Mancha Branca (WSSV) é constituído por DNA e todos os animais da ordem Decapoda mostraram-se sensíveis a esse agente, independente da salinidade. Outros organismos também são susceptíveis ao WSSV, desde poliquetas a lagostas. A transmissão pode ocorrer por três formas: vertical, horizontal ou por via hídrica. A WSSD recebeu esse nome devido as manchas brancas de mineralização que se formam na carapaça de camarões doentes, entretanto elas não podem ser consideradas como um sinal patognomônico. Para o diagnóstico recomenda-se realizar anamnese, exame a fresco, histopatológico e confirmar com algum teste molecular, como PCR ou LAMP. Não há tratamento eficaz e a prevenção é a melhor solução. Desse modo, como o Brasil é um país com destaque na sua produção de Litopenaeus vannamei, e que está buscando ganhar o mercado externo, torna-se imprescindível ampliar os estudos dessa enfermidade.
\end{abstract}

Palavras-chave: aquicultura; carcinicultor; crustáceo; pescado.

\begin{abstract}
Shrimp farming is an expanding profitable economic activity whose main obstacles are viral disease outbreaks. Among those, the White Spot Syndrome Disease (WSSD) stands out because of its virulence and mortality rate. The first outbreak report was in Asia in 1992, and since then the agent has spread to shrimp farming worldwide. The White Spot Syndrome Virus (WSSV) is constituted by DNA and all animals of the Decapoda order are sensitive to this agent, independently of salinity. Several other organisms are also susceptible to WSSV, from polychaetes to lobsters. Infection can occur in three ways: vertical; horizontal; or by water. The White Spot designation was given because of the mineralization white spots that form on the carapace of sick shrimps, however they may not be considered pathognomonic. For the diagnosis, it is recommended to perform anamnesis, fresh examination, histopathology, and confirm with a molecular test such as PCR or LAMP. There is no effective treatment and prevention is the best solution. Thus, as Brazil is a great producer of L. vannamei, and is seeking to domite the foreign market, it is essential to expand the study of this disease.
\end{abstract}

Keywords: aquaculture; shrimp grower; crustacean; fish.

\section{Introdução}

A carcinicultura é uma atividade lucrativa, entretanto muito sensível a surtos de doenças, que constituem um dos entraves no seu desenvolvimento sustentável (Barracco, 2004; FAO, 2014). Os camarões em cultivo podem ser

acometidos por doenças não infecciosas, causadas por agentes abióticos (má nutrição, toxinas e efeitos genéticos), e por bióticos (bactérias, vírus, fungos e parasitos) (Lightner, 1996; 2005; Flegel et al., 2004). 
As doenças infecciosas são o principal limitador da carcinicultura em muitos países, como está evidenciado desde a década de 1980, quando houve a rápida expansão das criações e favorecimento à dispersão de agentes patogênicos, e consequentemente, surgimento de surtos (Lightner, 1996; 2005; Barracco, 2004; Flegel et al., 2004). Dentre os agentes patogênicos, destacam-se os vírus como principais responsáveis pelo prejuízo econômico e limitante para o desenvolvimento da carcinicultura (Lightner, 1996; 2005; Flegel et al., 2004). Dentre os vírus que acometem os cultivos de camarões no mundo todo, o vírus da Mancha Branca se destaca pela sua alta morbidade e mortalidade (Sanchez-paz, 2010; Cavalli et al., 2011; Bateman et al., 2012; OIE, 2017a; 2017b Valdez et al., 2014).

Objetivou-se realizar essa revisão de literatura abordando a Síndrome da Mancha Branca, considerada a relevância sanitária e econômica para a carcinicultura brasileira.

\section{Enfermidades em Camarões}

$\mathrm{O}$ surgimento de surtos de doenças em camarões de cultivo, semelhantemente a outras espécies, depende de uma gama de fatores interligados, envolvendo ambiente, patógeno e hospedeiro. Nesse contexto, a simples presença de apenas um ou dois elementos, como por exemplo, do agente infeccioso, ou até mesmo deste último e hospedeiro susceptível, não garante $o$ desenvolvimento da doença, necessitando da interação dos três elementos direcionados, para que ela ocorra e gere perdas (Snieszco, 1974; Lightner e Redman, 1998).

De modo geral, essa virose causou surtos com altas taxas de mortalidade em diversos países asiáticos, nos quais causaram grandes perdas econômicas (Kono et al., 2004), como consequência da rápida replicação e a alta virulência do WSSV (Sánchez-paz, 2010).

\section{Estrutura viral}

O Vírus da Síndrome da Mancha Branca (WSSV) é o agente causador da Doença da Síndrome da Mancha Branca (WSSD) (Lightner, 2011; OIE, 2017b). O WSSV é o único membro do gênero Whispovirus, dentro da família Nimaviridae, designado assim pelo Comitê Internacional de Taxonomia de Vírus (ICTV) (OIE, 2017b). Já foram isolados diversos WSSV com pequenos polimorfismos genéticos (variantes), no entanto, a Nimaviridae é uma família recentemente identificada, e portanto, compreende-se que o conceito de espécies está sujeito a mudança conforme os estudos forem avançando (OIE, 2017b).

Os WSSV medem 80-120 nm de diâmetro e 250-380 nm de comprimento, são descritos de forma ovoide ou elipsoide, se assemelhando a um bacilo, com simetria regular (Durand et al., 1997; van Hulten et al., 2001). É considerado um vírus de tamanho grande, envelopado, de DNA de cadeia dupla (dsDNA) e possui densidade em torno de 1,2 $\mathrm{g} / \mathrm{mL}$ (Lightner, 2011).

Sua sequência genética completa da fita dupla de DNA, foi descrita por van Hulten et al. (2001) e esses pesquisadores conseguiram identificar 292,967 nucleotídeos. Kumar et al. (2018) conseguiram sequenciar, pela primeira vez, o genoma completo do WSSV isolado na Índia e Oakey e Smith (2018) na Austrália, além disso variações em genomas conhecidos do WSSV estão sendo encontradas (Piamsomboon et al., 2018), sugerindo que pode estar ocorrendo mobilidade de WSSV de um país para outro e assim ocasionando as variações genéticas.

No Brasil, Dantas et al. (2018) conseguiram a sequência genética completa de WSSV isolados no Brasil e verificaram que se assemelha filogeneticamente aos isolados em México e Tailândia.

\section{Viabilidade Viral}

Momoyama et al. (1998) verificaram que esse vírus consegue se manter viável em água salgada por até 120 dias a $15^{\circ} \mathrm{C}$, e a medida que a temperatura aumenta, o tempo de viabilidade diminui, chegando a até 30 dias a $30^{\circ} \mathrm{C}$.

Kumar et al. (2013) comprovaram a viabilidade em água salgada por até 12 dias, 19 dias em lagoas de sedimento, independente da secagem ao sol e em condições não drenáveis, o vírus permaneceu viável por até 35 dias. Essa resistência no ambiente dificulta o saneamento das fazendas, já que os viveiros precisariam passar muito tempo sem cultivo, além de requerer outras medidas higiênicas, como a adição de químicos para inativação viral.

$\mathrm{O}$ agente pode ser inativado em tempo menor que 120 minutos a $50^{\circ} \mathrm{C}$ ou por menos de 1 minuto a $60^{\circ} \mathrm{C}$ (OIE, 2017b). A temperatura ótima para manutenção desse vírus, está situada no intervalo entre 18 e $30^{\circ} \mathrm{C}$ (Vidal et al., 2001; Granja et al., 2003). Essa faixa de temperatura ótima do vírus coincide com as temperaturas esperadas na 
região nordeste, o que torna ainda mais difícil evitar a proliferação desse vírus.

Martorelli et al. (2010) defenderam a possibilidade de que o WSSV pode ser carreado por grandes distâncias, por correntes marítimas. Dessa forma, surtos que ocorreram no Brasil seriam a fonte de vírus que contaminaram a Bahía Blanca- Argentina.

Essa teoria não é tão bem aceita, uma vez que o WSSV é encontrado largamente na natureza, tanto em camarões nativos (Vazquez-sauceda et al., 2016) como em outras espécies carreadoras (Das et al., 2016), podendo assim ter infectado a Bahía Blanca, sem necessariamente ser proveniente do Brasil.

\section{Animais Susceptíveis e Vias de Transmissão}

Todos os membros da ordem Decapoda, independente da salinidade de seu ambiente natural, mostraram-se sensíveis ao WSSV (Figura 1) (Lightner, 1996; Flegel, 1997; Maeda et al., 2000; Stentiford et al., 2009). Corroborando com essa afirmação, a OIE (2017b) registrou a infecção em diversas espécies selvagens. Lightner (1996) afirmou que o camarão pode se infectar com o WSSV em todas as fases de sua vida, de ovos a reprodutores.

A transmissão do WSSV pode ocorrer reconhecidamente por três modos: vertical (transóvulo); horizontal, pelo consumo de tecido infectado (por exemplo, o canibalismo, predação) e por via de veiculação hídrica (OIE, 2017b).

As investigações quanto a possíveis susceptíveis são inúmeras, tamanha a sua importância na biosseguridade dentro dos cultivos de camarão. Sabe-se que os zooplâncton possuem capacidade de serem vetores do WSSV (Zhang et al., 2006), contudo, somente quando eclodidos, pois em forma de ovo não se conseguiu comprovar a infecção por WSSV (Yan et al., 2004). PorchasCornejo et al. (2017) conseguiram provar que o WSSV está presente em diversos grupos taxonômicos de zooplâncton, que são comumente encontrados em águas de cultivo, porém negligenciados na epidemiologia da WSSD.

Além dos zooplâncton, algumas poliquetas (vermes aquáticos) foram identificadas como possível fonte de infecção na carcinicultura (Vijayan et al., 2005), caranguejos (Lo et al., 1996; Ding et al., 2015; Powell et al., 2015; Das et al., 2016), lagostas (Lo et al., 1996; Musthaq et al., 2006), insetos da família Ephydridae (Lo et al., 1996), lagostim (Huang et al., 2015), copépodes
(Zhang et al., 2008) e até artêmia (Zhang et al., 2010; Li et al., 2003), que é utilizada na alimentação dos camarões, tornando ainda maior o risco de surtos da doença.

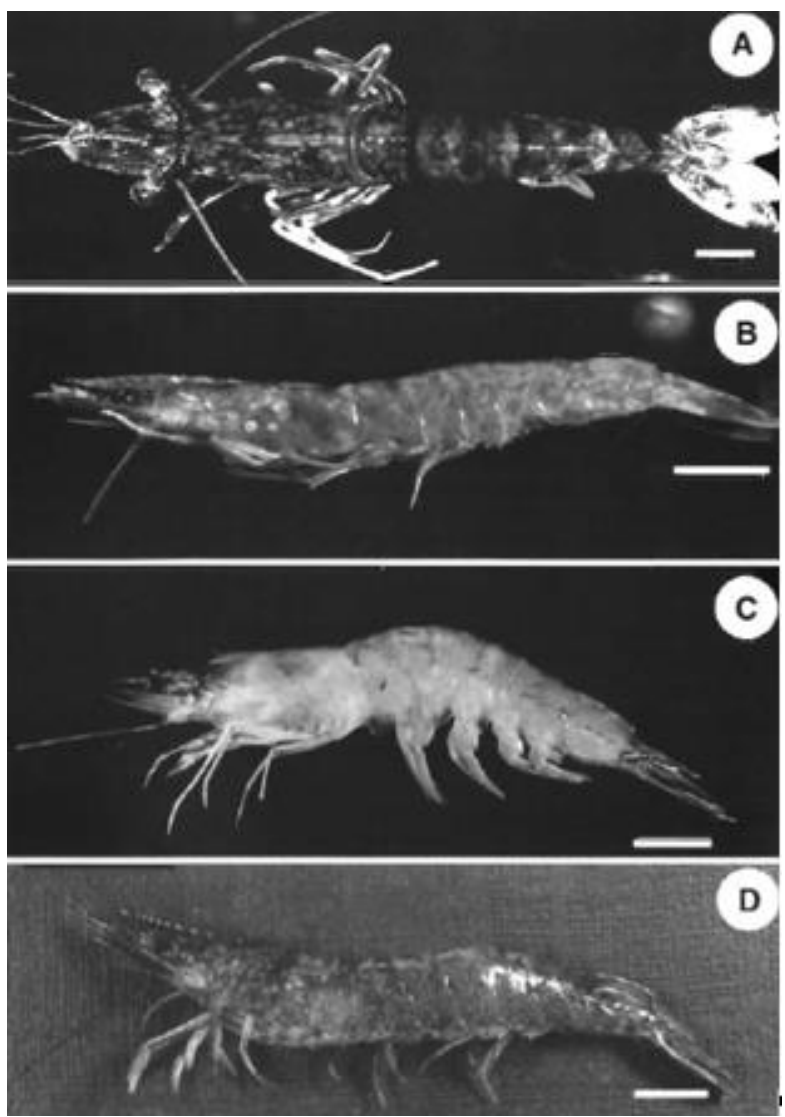

Figura 1. Camarões marinhos cultivados infectados com o Vírus da Síndrome da Mancha Branca (WSSV). (A) Penaeus monodon, (B) P. japonicus, (C) P. penicillatus, (D) Metapenaeus ensis. Escala da barra $=1 \mathrm{~cm}$. Fonte: Lo et al. (1996).

É possível encontrar na natureza, animais, inclusive membros da ordem Decapoda, sem nenhuma característica macroscópica de infecção por WSSV. Acredita-se que esses animais podem estar com uma infecção crônica, ou que a carga viral presente naquele ambiente não fosse suficiente para desencadear a doença (Hill, 2002; Peña et al., 2007; Meng et al., 2009).

Chapman et al. (2004) justificaram que aquela ausência de infecções graves, pode ser relacionada a não sobrevivência dos animais doentes, uma vez que estariam mais vulneráveis a predação ou a progressão rápida da WSSD. Deste modo, os autores explicaram o fato de encontrar animais infectados com o WSSV, sem a presença de sinais clínicos da doença.

\section{Ocorrência}

Registrou-se o primeiro aparecimento do WSSV no noroeste da Ásia por volta de 1992. A 
partir dali o vírus se dispersou rapidamente pela maioria dos cultivos de camarões da Ásia e da região Indo Pacífico, sendo atingidos os países da China, Japão, Coreia, Tailândia, Indonésia, Taiwan, Vietnam, Malásia e Índia. Facilitou a dispersão do vírus, juntamente com muitos outros patógenos, a necessidade de transporte de camarão vivo, bem como a falta de embargos (Pantoja e Lightner, 2014).

Alguns anos depois, em 1995, registrou-se o primeiro caso de WSSD no hemisfério ocidental, em uma propriedade no sul do estado do Texas, Estados Unidos da América (EUA). Suspeita-se que o vírus tenha sido introduzido por camarões importados de locais afetados pelo WSSV na Ásia (Pantoja e Lightner, 2014).

Posteriormente, por volta do final do ano de 1999, confirmou-se o primeiro caso de WSSV na América Central, México, Nicarágua, Honduras, Costa Rica, Panamá, e, nos anos seguintes, Equador, Peru, Colômbia e Brasil (Pantoja e Lightner, 2014).

Em outros países fora das américas também já foram registrados casos de Síndrome da Mancha Branca, como a Arábia Saudita (2010), Moçambique (2011) e Madagascar (2012) (Tang et al., 2012; 2013).

A Austrália era considerada livre de WSSV, até o primeiro registro de surto em 2016, e em 2018, ainda ocorrendo surtos, foi identificado o genoma completo do WSSV isolado lá (Oakey e Smith, 2018).

\section{Perfil da Doença}

Surtos de WSSD são relacionados diretamente com o manejo, como densidades impróprias, mudanças bruscas de salinidade ou de temperatura (Vidal et al., 2001; Granja et al., 2003) ou até mesmo, a própria desova (Lin et al., 2012).

Relata-se que na fase aguda da infecção, os camarões sofrem uma redução do apetite, letargia e sua cutícula pode soltar-se. Pode-se também, observar algumas manchas brancas de aproximadamente 2,0 $\mathrm{mm}$ de diâmetro (podendo se aglutinar em placas maiores), no lado interno da carapaça. Essas manchas, que deram o nome a doença, podem também estar presentes em qualquer parte da superfície interior do exoesqueleto (Figura 2) (Lightner, 2011; OIE, 2017b).

As manchas brancas são resultado de depósitos de sais de cálcio pelo epitélio cuticular infectado com WSSV (Lightner, 2011). Mesmo que ligadas fortemente a WSSD, as manchas brancas não devem ser consideradas como patognomônicos, uma vez que podem ser consequência de alta alcalinidade, interação bacteriana, bem como confundidas com variações de cores como tons de rosa e vermelho encontradas na superfície do exoesqueleto dos camarões (OIE, 2017b).

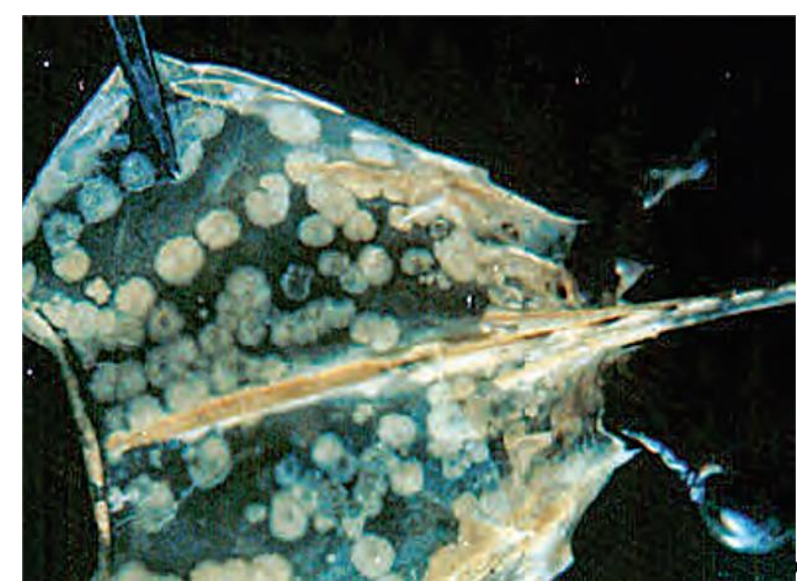

Figura 2. Visualização de manchas brancas na parte interna da carapaça de um camarão (Penaeus monodon) juvenil, infectado com Vírus da Síndrome da Mancha Branca (WSSV). Fonte: Morales e CuéllarAnjel (2014).

Encontrou-se registros que em criações onde aquelas alterações foram notadas, houve altas taxas de mortalidades nos cultivos de camarão, chegando até a 100\% em poucos dias (Lightner, 2011; OIE, 2017b).

O WSSV tem tropismo pelos tecidos ecto e mesodérmico, porém parece ter uma maior predileção pelo epitélio cuticular e tecidos conjuntivos subcuticulares (Wongteerasupaya et al., 1995). Mesmo infectando o tecido conjuntivo subjacente no hepatopâncreas e intestino dos camarões, as células epiteliais destes dois órgãos, não se infectam, uma vez que são de origem endodérmica (OIE, 2017b). Esse vírus também mostra tropismo por órgãos reprodutivos (Lo et al., 1997).

Usualmente um núcleo infectado por WSSV contêm apenas um corpo de inclusão (Lightner, 2011). Em preparações de "squash" de epitélio cuticular e/ou brânquias, é possível visualizar núcleos hipertrofiados, e em animais com altos níveis de infecção, identifica-se facilmente inclusões intracelulares eosinofílicas (OIE, 2017b). Em preparos histológicos visualizam-se inclusões semelhantes em epitélio cuticular, tecido conectivo, e com menor frequência, em epitélio de glândula antenal, membrana das células de órgãos 
linfoides, tecidos hematopoiéticos e coração (Lightner, 2011).

\section{Diagnóstico}

Para se realizar o diagnóstico de WSSD deve-se dispor da anamnese, informações relativas ao local, condições de criação e dados inerentes ao episódio que despertou a investigação (Morales e Cuéllar-anjel, 2014). Quando possível, deve-se o exame clínico e realizar o exame a fresco. Pode-se complementar com exames histopatológicos, testes moleculares como o Loop-medited Isothermal Amplification (ou Amplificação Isotérmica Mediada por Loop - LAMP), Polymerase Chain Reaction (ou Reação em Cadeia de Polimerase PCR) e hibridização in situ (Morales e Cuéllaranjel, 2014; OIE, 2017a; 2017b).

Usualmente, para concluir o diagnóstico utiliza-se o exame a fresco, o histopatológico e é aconselhável a utilização de um método diagnóstico molecular, como por exemplo, hibridização in situ, LAMP ou PCR (Lightner 2011; OIE, 2017b). O exame histopatológico pode servir como instrumento de seleção para as amostras a serem testadas nos exames moleculares. Ao utilizar diferentes métodos diagnósticos, podese comparar os dois e identificar em qual momento cada um pode ser melhor utilizado (Yoganandhan et al., 2003; Jaroenram et al, 2009).

Os únicos testes recomendados, pela OIE (2017b), para realizar vigilância em animais juvenis e adultos, bem como diagnóstico presuntivo e o definitivo são PCR e LAMP. Dentre esses dois, a LAMP se destaca por ser menos onerosa, ter uma reação mais simples e de maior eficiência, quando comparado com PCR (Parida, et al., 2008). Também se constatou que a LAMP possui maior sensibilidade, especificidade $\mathrm{e}$ estabilidade durante a realização do teste (Dhama et al., 2014).

A busca por ferramentas que permitam um estudo mais aprofundado do comportamento do vírus, bem como promover alternativas de meios de diagnóstico, especialmente voltados para pesquisa, é constante, como por exemplo o caso relatado por Hipolito et al. (2012), no qual usaram pela primeira vez no Brasil, a técnica de microscopia imunoeletrônica com coloração negativa, para ilustrar infeção por WSSV (Figura 3).

\section{Prevenção e Tratamento}

Não há vacina nem tratamento para a WSSD (OIE, 2017b), isso pode ser explicado pelo fato dos camarões possuírem apenas um sistema imune inato ou natural, não permitindo assim a produção de anticorpos, e portanto, inviabilizando o desenvolvimento de vacinas (Barracco, 2004).

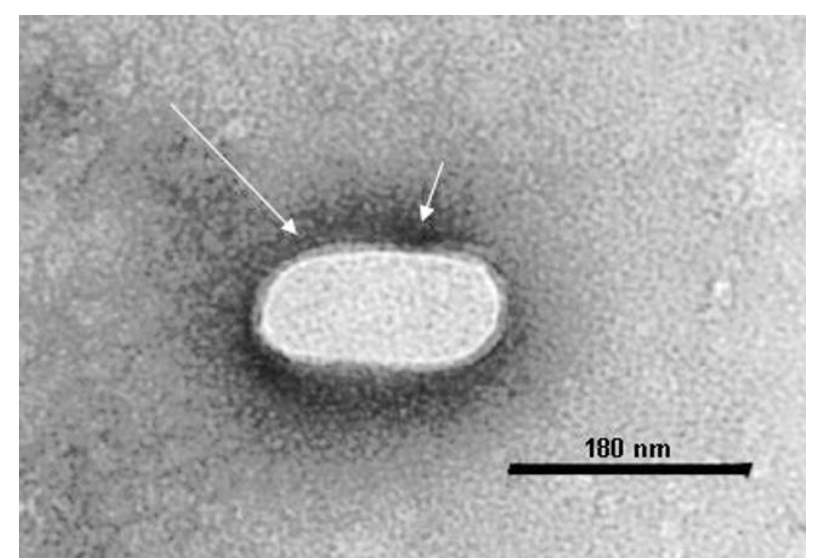

Figura 3. Fotomicrografia eletrônica da suspensão viral do Vírus da Síndrome da Mancha Branca (WSSV) proveniente de hepatopâncreas de Litopenaeus vannamei. Reparar nas partículas de forma oval e baciliformes (seta grande) e envelope exterior (seta menor). Fonte: Hipolito et al. (2012).

Há uma linha de pesquisa voltada a desenvolver "vacinas" contra o WSSV, porém como os crustáceos não possuem uma resposta imune humoral esse termo é errado, o que chamam de vacina é na verdade uma utilização de Bacillus subtilis, cuja ação parece ser inibidora do WSSV. Esse bacilo é administrado aos camarões por meio da alimentação e promovem um resultado positivo na prevenção da doença (Valdez et al., 2014).

Algumas proteínas que estão sendo isoladas da hemolinfa de lagostim demonstraram atuar na ação anti-WSSV e in vitro diminuíram a replicação viral deste agente ( $\mathrm{Li}$ et al., 2018). Taju et al. (2017) verificaram que a introdução da proteína $r$ VP28 com nanopartículas de CS/TPP na alimentação de camarões, é uma alternativa viável de estimular o sistema imune de crustáceos e assim auxiliar na resposta ao WSSV.

Há relatos de que vitamina $\mathrm{C}$, extratos de algas beta-glucana (fucoidano), probióticos e outros imunoestimulantes como a ferritina, podem melhorar a resistência ao WSSV (Chang, et al., 2003; Chotigeat, et al., 2004; Ye et al, 2015), sempre aliados as boas práticas de higiene e biosseguridade constantemente aplicadas como melhor forma de prevenção (OIE, 2017a).

A OIE (2017a) recomendou que ao comprar camarões de países ou zonas que não sejam zonas livres para WSSD, seja para consumo humano, animal, farmacêutico, ou outros, deve ser realizada quarentena e após esse período toda a água e 
detritos envolvidos no processamento desse camarão devem ser apropriadamente tratados, de modo a eliminar o vírus, para, então, poder ser descartados.

Medidas de biosseguridade em meios não diretos a carcinicultura devem ser tomadas, como por exemplo a inspeção de camarões congelados para isca de pesca (Hasson et al., 2006). Esse tipo de transmissão do vírus é preocupante, uma vez que irá direto para o meio ambiente, portanto, infecção direta para os animais que habitam locais que servem para captação de água e assim propagando o agente (Hasson et al., 2006).

Outra possível forma de disseminação do WSSV evidenciada nos últimos anos, é a comercialização de camarões como PET em aquários, visto que a fiscalização aplicada não leva em consideração a biosseguridade dos cultivos, representando um risco a carcinicultura (Mrugala, et al., 2015; Patoka, et al., 2016).

\section{Considerações Finais}

A WSSD é uma doença de relevância econômica, pois pode acabar com cultivos inteiros em poucos dias, portanto, é necessário a adoção de medidas de biosseguridade rigorosas de modo a evitar sua introdução nos cultivos. Alternativamente, deve-se ampliar o conhecimento e constante aprendizado para que possamos conviver com o WSSV, evitando prejuízos aos carcinicultores.

\section{Conflito de Interesse}

Os autores declaram não existir conflito de interesse.

\section{Referências}

Barracco, M.A. Mecanismos de resistência a doenças em crustáceos. In: Ranzani-Paiva, M.J.T.; Takemoto, R.M.; Lizama, M.L.A.P. Sanidade de organismos aquáticos. São Paulo: Varela, 2004. p. 51-74.

Bateman, K.S.; Tew, I.; French, C.; Hicks, R.J.; Martin, P.; Munro, J.; Stentiford, G.D. Susceptibility to infection and pathogenicity of white spot disease (wsd) in non-model crustacean host taxa from temperate regions. Journal of Invertebrate Pathology, 110: 340351, 2012.

Cavalli, L.S.; Romano, L.A.; Marins, L.F.; Abreu, P.C. First report of white spot syndrome virus in farmed and wild penaeid shrimp from Lagoa dos Patos estuary, southern Brazil. Brazilian
Journal of Microbiology, 42: 1176-1179, 2011.

Chang, C.F.; Su, M.S.; Chen, H.Y.; Liao, I.C. Dietary [beta]-1,3-glucan effectively improves immunity and survival of penaeus monodon challenged with white spot syndrome virus. Fish and Shellfish Immunology, 15: 297-310, 2003.

Chapman, R.W.; Browdy, C.L.; Savin, R.; Prios, S.; Wenner, E. Sampling and evaluation of white spot syndrome virus in commercially important Atlantic penaeid shrimp stocks. Disease of Aquatic Organisms, 59: 179-185, 2004.

Chotigeat, W.; Tongsupa; S.; Supamataya, K.; Phongdara; A. Effect of fucoidan on disease resistance of black tiger shrimp. Aquaculture, 233: 23-30, 2004.

Dantas, M.D.A.; Teixeira, D.G.; Silva-Portela, R.C.B.; Soares, P.E.T.; Lima, J.P.M.S.; AgnezLima, L.F.; Lanza, D.C.F. Direct sequencing of White spot syndrome virus from Brazil: genome assembly and new insights in phylogeny. Virus Research, 245: 52-61, 2018.

Das, S., Biswas, G., Ghoshal, T.K. Occurrence of pathogenic shrimp viruses in selected wild crab species of sunderban, India. Indian Journal of Fisheries, 63 (2): 14-146, 2016.

Dhama, K.; Kartlik, K.; Chakraborty, S.; Tiwari, R.; Kapoor, S.; Kumar, A.; Thomas, P. Loopmediated isothermal amplification of DNA (lamp): a new tool lights the world of diagnosis of animal and human pathogens: a review. Pakistan Journal of Biological Sciences, 17(2): 151-166, 2014.

Ding, Z.; Yao, Y.; Zhang, F.; Wan, J.; Sun, M.; Liu, H.; Zhou, G.; Tang, J.; Pan, J.; Xue, H.; Zhao, $Z$. The first detection of white spot syndrome virus in naturally infected cultured Chinese mitten crabs, Eriocheir sinensis in china. Journal of Virological Methods, 220: 49-54, 2015.

Durand, S.; Lightner, D.V.; Redman, R.M.; Bonami, J.R. Ultrastructure and morphogenesis of white spot syndrome baculovirus (WSSV). Diseases of Aquatic Organisms, 29: 205-211, 1997.

FAO - Food and Agriculture Organization of the United Nations. 2016. The state of world fisheries and aquaculture - contributing to food secutity and nutrition for all. Disponível em: < http://www.fao.org/3/a-i5555e.pdf>. Acesso em: 10 jan. 2018. 
Feijó, R.G.; Kamimura, M.T.; Oliveira-Neto, J.M,; Vila-Nova, C.M.V.M.; Gomes, A.C.S.; Coleho, M.G.L.; Vasconcelos, R.F.; Gesteria, T.C.V.; Martins, L.F.; Maggioni, R. Infectious myonecrosis virus and white spot syndrome virus co-infection in pacific white shrimp (Litopenaeus vannamei) farmed in Brazil. Aquaculture, 380-383: 1-5, 2013.

Flegel T.W. Major viral diseases of the black tiger prawn (penaeus monodon) in Thailand. World Journal of Microbiology and Biotechnology, 13: 433-442, 1997.

Flegel, T.W.; Nielsen, L.; Thamavit, T.; Kongtim, S.; Pasharawipas, T. Presence of multiple viruses in non-diseased, cultivated shrimp at harvest. Aquaculture, 240: 55-68, 2004.

Granja, C.B.; Aranguren, L.F.; Vidal, O.M.; Aragón, L.; Salazar, M. Does hyperthermia increase apoptosis in white spot syndrome virus (wssv)-infected Litopenaeus vannamei? Diseases of Aquatic Organisms, 54: 73-78, 2003.

Hasson, K.W.; Fan, Y.; Reisinger, T.; Venuti, J.; Varner, P.W. White spot syndrome virus (WSSV) introduction into the Gulf of Mexico and Texas freshwater systems through imported, frozen bait-shrimp. Diseases of Aquatic Organisms, 71: 91-100, 2006.

Hill, B. National and international impacts of white spot disease of shrimp. Bulletin- European Association of Fish Pathologists, 2: 58-65, 2002.

Hipolito, M.; Catroxo, M.H.B.; Martins, A.M.C.R.P.F.; Melo, N.A.; Pituco, E.M.; Galleti, N.T.C.; Ranzani-Paiva, M.J.T.; Mouriño, J.L.P.; Ferreira, C.M. Detection of white spot syndrome virus in Brazil using negative staining, immunoelectron microscopy and immunocytochemistry techniques. International Journal of Morphology, 30(2): 761-768, 2012.

Huang, J.; Li, F.; Wu, J.; Yang, F. White spot syndrome virus enters crayfish hematopoietic tissue cells via clathrin-mediated endocytosis. Virology, 486: 35-43, 2015.

Jaroenram, W.; Kiatpathomchai, W.; Flegel, T.W. Rapid and sensitive detection of white spot syndrome virus by loop-mediated isothermal amplification combined with a lateral flow dipstick. Molecular and Cellular Probes, 23: 65-70, 2009.

Kono, T.; Savan, R.; Sakai, M.; Itami, T. Detection of white spot syndrome virus in shrimp by loop- mediated isothermal amplification. Journal of Virological Methods, 115: 59-65, 2004.

Kumar, K.V.; Shekhar, M.S.; Otta, S.K.; Karthic, K.; Kumar, J.A.; Gopikrishna, G.; Vijayan, K.K. First Report of a Complete Genome Sequence of White spot syndrome virus from India. Genome Announcements, 6(8): 1-2, 2018.

Kumar, S.S.; Bharathi, R.A.; Rajan, J.J.S.; Alavandi, $\quad$ S.V.; Poornim, M.; Balasubramanian, C. P.; Ponniah, A.G. Viability of white spot syndrome virus (WSSV) in sediment during sun-drying (drainable pond) and under non-drainable pond conditions indicated by infectivity to shrimp. Aquaculture, 402-403: 119-126, 2013.

Li, D.; Chang, X.; Xie, X.; Zheng, S.; Zhang, Q.; Jia, S.; Wang, K.; Liu, H. A thymosin repeated protein1 reduces white spot syndrome virus replication in red claw crayfish Cherax quadricarinatus. Developmental and Comparative Immunology, 84: 109-116, 2018.

Li, Q.; Zhang, J.; Chen, Y.; Yang, F. White spot syndrome virus (WSSV) infectivity for artemia at different developmental stages. Diseases of Aquatic Organisms, 57: 261-264, 2003.

Lightner, D.V. A Handbook of shrimp pathology and diagnostic procedures for diseases of cultured penaeid shrimp. $1^{\text {st }}$ ed. Baton Rouge: World Aquaculture Society, 1996.

Lightner, D.V. Biosecurity in shrimp farming: pathogen exclusion through use of SPF stock and routine surveillance. Journal of the World Aquaculture Society, 36: 229-248, 2005.

Lightner, D.V. Virus diseases of farmed shrimp in the western hemisphere (the americas): a review. Journal of Invertebrate Pathology, 106: 110-130, 2011.

Lightner, D.V.; Redman, R.M. shrimp diseases and current diagnostic methods. Aquaculture, 164: 201-220, 1998.

Lin, S.; Hsia, H.; Liu, W.; Huang, J.; Liu, K.; Chen, W.; Yeh, Y.; Huang, Y.; Lo, C.; Kou, G.; Wang, H. Spawning stress triggers WSSV replication in brooders via the activation of shrimp STAT. Developmental and Comparative Immunology, 38: 128-135, 2012.

Lo, C.; Ho, C.; Peng, S.; Chen, C.; Hsu, H.; Chiu, Y.; Chang, C.; Lui, K.; Su, M.; Wang, C.; Kou, G. White spot syndrome baculovirus (WSBV) detected in cultured and captured shrimp, 
crabsand other arthropods. Diseases of Aquatic Organisms, 27: 215-225, 1996.

Lo, C.F.; Aoki, T.; Bonami, J.R.; Flegel, T.W.; Leu, J.H.; Lightner, D.V.; Stentiford, G.; Söderhäll, K.; Walker, P.W.; Wang, H.C.; Xun, X.; Yang, F.; Vlak, J.M. Nimaviridae. IN: King A.M.Q., Adams M.J., Carstens E.B., e Lefkowitz E.J. Virus taxonomy: classification and nomenclature of viruses: ninth report of the International Committee on Taxonomy of Viruses. San Diego: Elsevier Academic Press, 2012. p. 229-234.

Lo, C.F.; Ho, C.H.; Chen, C.H.; Liu, K.F.; Chiu, Y.L.; Yeh, P.Y.; Peng, S.E.; Hsu, H.C.; Liu, H.C.; Chang, C.F.; Su, M.S.; Wang, C.H.; Kou, G.H. Detection and tissue tropism of white spot syndrome baculovirus (WSBV) in captured brooders of Penaeus monodon with a special emphasis on reproductive organs. Diseases of Aquatic Organisms, 30: 53-72, 1997.

Maeda, M.; Itami, T.; Mizuki, E.; Tanaka, R.; Yoshizu, Y.; Doi, K.; Yasunaga-Aoki, C.; Takahashi, Y; Kawarabata, T. Red swamp crawfish (Procambarus clarkii): an alternative experimental host in the study of white spot syndrome virus. Acta Virologica, 44: 371-374, 2000.

Martorelli, S.R.; Overstreet, R.M.; Jovonovich, J.A. First report of viral pathogens WSSV and IHHNV in argentine crustaceans. Bulletin of Marine Science, 86 (1): 117-131, 2010.

Meng, X.; Jang, I.; Seo, H.; Cho, Y. White spot syndrome virus quantification in blue crab Portunus trituberculatus hatchery-produced larvae and wild populations by taqman realtime PCR, with an emphasis on the relationship between viral infection and crab health. Aquaculture, 291: 18-22, 2009.

Momoyama, K., Hiraoka, M., Nakano, H., Sameshima, M. Cryopreservation of penaeid rod-shaped DNA virus (PRDV) and its survival in sea water at different temperatures. Fish Pathology, 33(2): 95-96, 1998.

Morales, V.Q.; Cuéllar-Anjel, J. Guía técnica patología e inmunología de camarones penaeidos. Rep. de Panamá: OIRSA, 2014. 382 p.

Mrugala, A; Kova-Balcarova, E.; Chucholl, C.; Resino, S.C.; Viljamaa-Dirks, S.; Vukic, J.; Petrusek, A. Trade of ornamental crayfish in Europe as a possible introduction pathway for important crustacean diseases: crayfish plague and white spot syndrome. Biological Invasions, 17(5): 1313-1326, 2015.

Musthaq, S.S.; Sudhakaran, R.; Balasubramanian, G.; Hamees, A.S.S. Experimental transmission and tissue tropism of white spot syndrome virus (WSSV) in two species of lobsters, Panulirus homarus and Panulirus ornatus. Journal of Invertebrate Pathology, 93: 75-80, 2006.

Nakano H.; Hiraoka M.; Sameshima M.; Kimura T.; Momoyama K. Inactivation of penaeid rodshaped DNA virus (PRDV), the causative agent of penaeid acute viraemia (PAV), by chemical and physical treatments. Fish Pathology, 33: 65-71, 1998.

Oakey, H.J.; Smith, C.S. Complete genome sequence of a white spot syndrome virus associated with a disease incursion in Australia. Aquaculture, 484: 152-159, 2018.

OIE - World Organisation For Animal Health. Manual of diagnostic tests for aquatic animals, de 13 de julho de 2017. 2017b. Disponível em: <http://www.oie.int/fileadmin/Home/eng/Healt h_standards/aahm/current/chapitre_wsd.pdf >. Acesso em: 19 maio 2018.

OIE - World Organisation For Animal Health. Aquatic animal health code, de quatro de julho de 2017. 2017a. Disponível em: <http://www.oie.int/fileadmin/Home/eng/Healt h_standards/aahc/current/chapitre_wsd.pdf >. Acesso em: 19 maio 2018.

Pantoja, C.; Lightner, D.V. Virus del síndrome de la mancha blanca (white spot syndrome vírus, WSSV) In: Morales, V. y J. Cuéllar-Anjel. Guía técnica: patología e inmunología de camarones penaeidos. Rep. de Panamá: OIRSA, 2014. p.111-120.

Parida, M.; Sannarangaiah, S.; Dash, P.K.; Rao, P.V.L.; Morita, K. Loop mediated isothermal amplification (LAMP): a new generation of innovative gene amplification technique; perspectives in clinical diagnosis of infectious diseases. Reviews in Medical Virology, 18: 407-421, 2008.

Patoka, J.; Blaha, M.; Devetter, M.; Rylkova, K.; Cadkova, Z.; Kalous, L. Aquarium hitchhikers: attached commensals imported with freshwater shrimps via the pet trade. Biological Invasions, 18 (2): 457-461, 2016.

Peña, L.D.; Lavilla-Pitogo, C.R.; Villar, C.B.R.; Paner, M.G.; Sombito, C.D.; Capulos, G.C. Prevalence of white spot syndrome virus (WSSV) 
in wild shrimp Penaeus monodon in the Philippines. Diseases of Aquatic Organisms, 77: 175-179, 2007.

Piamsomboon, P.; Chaweepack, T.; Han, J.E.; Tang, K.F.; Wangtavatchai, J. Genetic variation of white spot syndrome virus (WSSV) in Pacific white shrimp Litopenaeus vannamei (Boone 1931) culture of Thailand. Aquaculture Reasearch, 49: 265-272, 2018.

Porchas-Cornejo, M.A.; Álvarez-Ruiz, P.; Álvarez-Tello, F.J.; Martínez-Porchas, M.; Martínez-Córdova, L.R.; López-Martínez, J.; García-Morales, R. Detection of the white spot syndrome virus in zooplankton samples collected off the coast of Sonora, Mexico. Aquaculture Research, 49: 48-56, 2018.

Powell, J.W.B.; Browdy, C.L.; Burge, E.J. Blue crabs Callinectes sapidus as potential biological reservoirs for white spot syndrome virus (WSSV). Diseases of Aquatic Organisms, 113: 163-167, 2015.

Sanchez-Paz, A. White spot syndrome virus: an overview on an emergent concern. Veterinary Research, 41 (6): 1-34, 2010.

Snieszko, S.F. The effects of environmental stress on outbreaks of infectious diseases of fishes. Journal of Fish Biology, 6: 197-208, 1974.

Stentiford, G.D.; Bonami, J.R.; Alday-Sanz, V. A critical review of susceptibility of crustaceans to taura syndrome, yellow head disease and white spot disease and implications of inclusion of these diseases in European legislation. Aquaculture, 291: 1-17, 2009.

Taju, G.; Kumar, D.V.; Majjed, S.A.; Vimal, S.; Tamizhvanan, S.; Kumar S.S.; Sivakumar, S.; Basha, A.N.; Haribabu, P.; Kannabiran, K.; Hameed, A.S.S. Delivery of viral recombinant VP28 protein using chitosan tripolyphosphate nanoparticles to project the white leg shrimp, Litopenaeus vannamei from white spot syndrome virus infection. International Journal of Biological Macromolecules, 107: 1131-1141, 2018.

Tang, K.F.J.; Le Groumellec, M.; Lightner D.V. Novel, closely related, white spot syndrome virus (WSSV) genotypes from Madascar, Mozambique and The Kingdom of Saudi Arabia. Diseases of Aquatic Organisms, 106: 1-6, 2013.

Tang, K.F.J.; Navarro S.A.; Pantoja, C.R.; Aranguren F.L.; Lightner D.V. New genotypes of white spot syndrome virus (WSSV) and taura syndrome virus (TSV) from Kingdom of Saudi
Arabia. Diseases of Aquatic Organisms, 99: 179-185, 2012.

Valdez, A.; Yepiz-Plascencia, G.; Ricca, E.; Olmos, J. First Litopenaeus vannamei WSSV $100 \%$ oral vaccination protection using CotC: Vp26 fusion protein displayed on Bacillus subtilis spores surface. Journal of Applied Microbiology, 117: 347-35, 2014.

Van Hulten, M.C.W.; Witteveldt, J.; Peters, S.; Kloosterboer, N.; Tarchini, R.; Fiers, M.; Sandbrink, H.; Lankhorst, R.K.; Vlak, J.M. The white spot syndrome virus DNA genome sequence. Virology, 286: 7-22, 2001.

Vazquez-Sauceda, M.L.; Sánchez-Martínez, J.G.; Pérez-Castañeda, R.; Rábago-Castro, J.L.; Aguirre-Guzmán, G.; Vargas-Cruz, D.Y. White spot syndrome virus (WSSV) and necrotizing hepatopancreatitis (NHP) detection in wild shrimp of the San Andrés Lagoon, Mexico. Revista de Biología Marina y Oceanografía, 51(2): 455-459, 2016.

Vidal, O.M.; Granja, C.B.; Aranguren; F.; Brock, J.A.; Salazar, M. A profound effect of hyperthermia on survival of Litopenaeus vannamei juveniles infected with white spot syndrome virus. Journal World Aquaculture Society, 32: 364-372, 2001.

Vijayan K.K.; Stalin Raj V.; Balasubramanian C.P.; Alavandi S.V.; Thillai Sekhar V.; Santiago T.C. Polychaete worms - a vector for white spot syndrome virus (WSSV). Diseases of Aquatic Organisms, 63: 107-111, 2005.

Wongteerasupaya, C.; Vickers, J.E.; Sriurairatana, S.; Nash, G.L.; Akarajamorn, A.; Boonsaeng, V.; Panyim, S.; Tassanakajon, A.; Withyachumnarnkul, B.; Flegel, T.W. A nonoccluded, systemic baculovirus that occurs in cells of ectodermal and mesodermal origin and causes high mortality in the black tiger prawn Penaeus monodon. Diseases of Aquatic Organisms, 21: 69-77, 1995.

Yan D.C.; Dong S.L.; Huang J.; Yu X.M.; Feng M.Y.; Liu X.Y. White spot syndrome virus (WSSV) detected by PCR in rotifers and rotifer resting eggs from shrimp pond sediments. Diseases of Aquatic Organisms, 59: 69-73, 2004.

Ye, T.; Wu, X.; Wu, W.; Dai, C.; Yuan, J. Ferritin protect shrimp Litopenaeus vannamei from WSSV infection by inhibiting virus replication. Fish \& Shellfish Immunology, 42: 138-143, 2015. 
Yoganandhan, K.; Sathish, S.; Murugan, V.; Narayanan, R.B.; Sahul Hameed, A.S. Screening the organs for early detection of white spot syndrome virus in Penaeus indicus by histopathology and PCR techniques. Aquaculture, 215: 21-29, 2003.

Zhang, J.; Dong, S.; Dong, Y.; Tian, X.; Cao, Y.; $\mathrm{Li}, \mathrm{Z}$; ; Yan, D. Assessment of the role of brine shrimp Artemia in white spot syndrome virus (WSSV) transmission. Veterinary Research Communications, 34(1): 25-32, 2010.
Zhang, J.; Dong, S.; Dong, Y.; Tian, X.; Hou, C. Bioassay evidence for the transmission of WSSV by the harpacticoid copepod Nitocra sp. Journal od Invertebrate Pathology, 97: 3339, 2008.

Zhang, J.; Dong, S.; Tian, X.; Dong, Y.; Liu, Y.; Yan, D. Studies on the rotifer (Brachionus urceus Linnaeus, 1758) as a vector in white spot syndrome virus (WSSV) transmission. Aquaculture, 261: 1181-1185, 2006. 